\title{
Effects on Aerosol Performance of Mixing of Either Budesonide or Beclomethasone Dipropionate With Albuterol and Ipratropium Bromide
}

\author{
Andrea S Melani MD
}

\begin{abstract}
BACKGROUND: Mixing of nebulized drugs is common in real life, but its consequences on aerosol output and granulometry are poorly known. METHODS: In an in vitro study I evaluated the effects on aerosol output, drug output, and aerosol particle size characteristics of mixing either beclomethasone dipropionate or budesonide with albuterol and ipratropium bromide. I tested the SideStream and VentStream-Pro nebulizers, run with the AirClinic compressor. Using the same fill volume in all experiments, I nebulized and evaluated each studied drug alone, and 2 drug mixtures: beclomethasone plus albuterol plus ipratropium; and budesonide plus albuterol plus ipratropium. I measured aerosol output via gravimetrics. I measured drug delivery by collecting the aerosol on a filter in the inspiratory limb, and the residual solution in the reservoir and the circuit after nebulization, and assayed those liquids with chromatography. I measured particle size distribution via cascade impaction. RESULTS: Mixing tended to reduce drug output and to increase mass median aerodynamic diameter with the SideStream, but not always with the VentStream-Pro. However, the drug output always remained satisfactory and the mass median aerodynamic diameters were within the respirable range. When nebulized alone, the respirable mass of bronchodilators ranged from $18 \%$ to $40 \%$ of the nominal dose; when mixed, it ranged from $13 \%$ to $37 \%$. When nebulized alone, the respirable mass of corticosteroids ranged from $10 \%$ to $24 \%$ of the nominal dose; when mixed, it ranged from $10 \%$ to $17 \%$. CONCLUSIONS: Both the SideStream and VentStream-Pro have good aerosol performance in nebulizing budesonide or beclomethasone dipropionate alone, and when mixed with albuterol and ipratropium bromide. Key words: nebulizer; drug administration; inhalation; aerosol therapy; inhalation therapy: COPD; asthma; corticosteroids; beclomethasone dipropionate; budesonide; albuterol; ipratropium bromide. [Respir Care 2011;56(3):319-326. (c) 2011 Daedalus Enterprises]
\end{abstract}

\section{Introduction}

Aerosolized bronchodilators and corticosteroids are the mainstay of pharmacologic management for asthma and COPD. The production of therapeutic aerosol requires spe-

\footnotetext{
Andrea S Melani MD is affiliated with Fisiopatologia e Riabilitazione Respiratoria, Policlinico Le Scotte, Azienda Ospedaliera Universitaria Senese, Siena, Italy.

Dr Melani has disclosed a relationship with Artsana.

Correspondence: Andrea S Melani MD, Fisiopatologia e Riabilitazione Respiratoria, Policlinico Le Scotte, Azienda Ospedaliera Universitaria Senese, Viale Bracci I-53100 Siena Italy. E-mail: a.melani@ao-siena.toscana.it.
}

DOI: $10.4187 /$ respcare.00955 cific delivery devices, such as inhalers and nebulizers. Although nebulizers are cumbersome and time-consuming, a meta-analysis of randomized controlled studies indicated that they are an appropriate and effective alternative to inhaler. ${ }^{1}$ Effective delivery of inhaled drugs to infants and elderly patients may be challenging, mainly due to inhaler misuse. Likewise, some elderly patients prefer nebulizer, not only for acute severe episodes of bronchospasm, but for regular long-term home use..$^{2-4}$ An exhaustive literature review revealed that there is a paucity of randomized controlled studies on nebulization of corticosteroids, as most research trials have employed metereddose inhalers. ${ }^{1}$ Additionally, although in vitro experiments can be a surrogate for in vivo investigation of respiratory drug delivery, ${ }^{5}$ extensive information about nebulized corticosteroids from in vitro studies is still not available. We know only that corticosteroids are usually formulated as 
Table 1. Drugs Studied

\begin{tabular}{|c|c|c|c|c|c|c|}
\hline Generic Name & Form & Brand Name & Manufacturer & $\begin{array}{l}\text { Concentration } \\
(\mathrm{mg} / \mathrm{mL})\end{array}$ & $\begin{array}{c}\text { Lot } \\
\text { Number(s) }\end{array}$ & $\begin{array}{l}\text { Dose } \\
\text { Volume } \\
(\mathrm{mL})\end{array}$ \\
\hline Albuterol sulfate & Inhalation solution, multiple-unit vial & Broncovaleas & Valeas, Milano, Italy & 5 & 336,337 & $0.5^{* \dagger}$ \\
\hline Ipratropium bromide & Inhalation solution, 2-mL vial & Atem & Chiesi, Parma, Italy & 0.25 & 072468 & $4.5 \ddagger$ \\
\hline Beclomethasone dipropionate & Inhalation suspension, 2-mL vial & Clenil & Chiesi, Parma, Italy & 0.4 & 070649 & $4.5 \S$ \\
\hline Budesonide & Inhalation suspension, 2-mL respule & Pulmaxan & AstraZeneca, Milan, Italy & 0.5 & HE615, 2206 & $4.5 \|$ \\
\hline \multicolumn{7}{|c|}{$\begin{array}{l}\text { * Formulation contains albuterol sulfate } 6 \mathrm{mg} / \mathrm{mL} \text {, equivalent to } 5 \mathrm{mg} / \mathrm{mL} \text { albuterol, in addition to p-hydroxibenzoate and water for injection. } \\
\dagger \text { This dose was added to } 4 \mathrm{~mL} \text { physiologic saline (Rinoflux Artsana, Grandate, Como, Italy, lot } 71490000 \text { ). } \\
\text { † Formulation contains ipratropium bromide, sodium phosphate monohydrate, disodium phosphate dehydrate, sodium chloride, and water. } \\
\text { § Formulation contains beclomethasone dipropionate, sodium chloride, polysorbate } 20 \text {, sorbitan laureate, and water. } \\
\| \text { Formulation contains budesonide, disodium ededate, polysorbate } 80 \text {, citric acid, sodium citrate, sodium chloride, and water. }\end{array}$} \\
\hline
\end{tabular}

suspensions and that the choice of nebulizer system can strongly affect the outcome of aerosol therapy. ${ }^{6-8}$

Another complication arises when bronchodilators and corticosteroids are simultaneously prescribed for nebulization: combining the drugs in the nebulizer for simultaneous nebulization is not recommended but is often done. ${ }^{9,10}$ A nationwide study in Italy with 745 patients with chronic lung diseases who regularly used nebulized bronchodilator at home, found that $88 \%$ of the patients combined the bronchodilator with the corticosteroid. ${ }^{10}$ Although no serious incompatibility is known when bronchodilators and corticosteroids are mixed, ${ }^{11-14}$ to my knowledge no previous study has measured the particle size distribution and aerosol output of corticosteroids when mixed with albuterol and ipratropium bromide (ipratropium).

I chose albuterol and ipratropium because they are widely used short-acting bronchodilators; budesonide because it is a well studied corticosteroid; and beclomethasone dipropionate (beclomethasone) because it has proven clinical value ${ }^{15}$ and is the most commonly nebulized corticosteroid in Italy. ${ }^{10} \mathrm{I}$ selected the SideStream (Artsana, Grandate, Como, Italy) and VentStream-Pro (Artsana, Grandate, Como, Italy) nebulizers because they are available worldwide and both can be powered by the double-piston AirClinic compressor (Artsana, Grandate, Como, Italy), which is known for high performance. The SideStream has a traditional continuous output, although enriched with an open-vent system through which extra air may be drawn into the nebulizer reservoir; VentStream-Pro is a breath-enhanced nebulizer.

The aim of this study was to evaluate the aerosol consequences of mixing budesonide or becomethasone with albuterol and ipratropium.

\section{Methods}

\section{Drugs}

Table 1 describes the tested drugs. One combined drug liquid consisted of $0.5 \mathrm{~mL}$ of the albuterol formulation,
$2 \mathrm{~mL}$ of the ipratropium formulation, and $2 \mathrm{~mL}$ of the beclomethasone formulation. The other consisted of $0.5 \mathrm{~mL}$ of the albuterol formulation, $2 \mathrm{~mL}$ of the ipratropium formulation, and $2 \mathrm{~mL}$ of the budesonide formulation. The mixtures were prepared in accordance with our usual clinical practice and the product-information sheet. All the experiments used a fill volume of $4.5 \mathrm{~mL}$, in accordance with common practice in Italy. ${ }^{10}$

\section{Nebulizers}

I unsystematically chose 6 SideStream and 6 VentStream-Pro nebulizers from standard commercial lots and water-tested them to determine intra-lot aerosol-output variability. I then selected the 2 units of each brand with the lowest aerosol-output variability at the mid-to-high aerosol-output range. Overall, there was less than 3\% aerosoloutput variation. Both nebulizers were driven with the double-piston AirClinic compressor. The compressor flow without external resistance was $17 \mathrm{~L} / \mathrm{min}$. The compressor flows through the operating SideStream and VentStreamPro were, respectively, $9 \mathrm{~L} / \mathrm{min}$ and $7 \mathrm{~L} / \mathrm{min}$, and the operating pressures were, respectively, 23 psi and 16 psi.

All experiments were carried out in triplicate, and the reported values are means from 3 experiments. The ambient temperature was $22 \pm 2{ }^{\circ} \mathrm{C}$ and the ambient relative humidity was $45-50 \%$.

\section{Aerosol Output}

With each drug and drug combination I gravimetrically measured (balance model E154, Gibertini, Bologna, Italy, precision $\pm 0.01 \mathrm{mg}$ ) the aerosol output. I weighed the nebulizer with the reservoir empty, after charging the reservoir with $4.5 \mathrm{~mL}$ of the investigated formulation, and after nebulization, and calculated the aerosol output as the weight difference before versus after nebulization, assuming a liquid density of $1.0 \mathrm{~g} / \mathrm{mL}$.

After charging the fill volume, I closed the circuit, connected the vacuum pump to the nebulizer mouthpiece, turned 


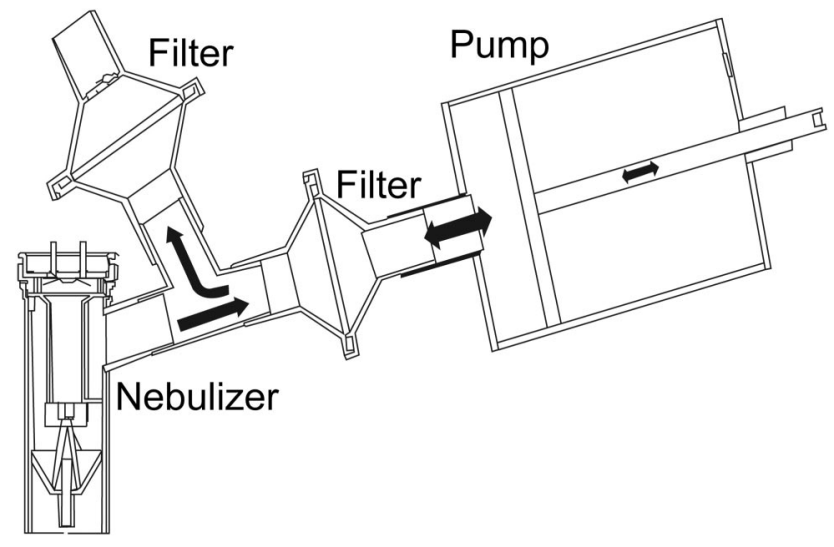

Fig. 1. Setup for testing drug output with the nebulizers.

on the pump (operated at $15 \mathrm{~L} / \mathrm{min}$ ), and after 10 seconds switched on the nebulizer compressor. I deemed nebulization complete when no visible aerosol had been produced for 60 seconds, without any shaking or tapping of the nebulizer.

\section{Drug Output}

Aerosol was captured on a filter (type A/E glass fiber filter, Pall, Port Washington, New York, lot 72303, which captures $>99 \%$ of aerosol particles at $15 \mathrm{~L} / \mathrm{min}$ ) in the inspiratory limb (Fig. 1) and eluted with a device designed for this purpose (DUSA [Dose Uniformity Sampling Apparatus], Copley Scientific, Nottingham, United Kingdom). After charging the nebulizer, I connected the nebulizer to the filter, and the filter to the vacuum pump, turned on the vacuum pump, and after 10 seconds switched on the nebulizer compressor. After nebulization was complete, the aerosol was eluted from the filter, and assayed with highperformance liquid chromatography (HP 1050, Hewlett Packard/Agilent Technologies, Palo Alto, California, with ChemStation REV.A.00.02 software, ChemStation, Houston, Texas) according to a standardized method. ${ }^{16}$

After nebulization, the residual drug liquid in the nebulizer reservoir and the circuit was also collected, mixed for homogeneity, and assayed. The medication concentrations were calculated based on standard calibration curves prepared with 8 known drug concentrations. The calibration curves for all the studied drugs had a correlation coefficient of $r \geq 0.999$. The nominal dose was calculated based on the drug concentration indicated in the productinformation sheet.

\section{Particle Size Distribution}

Aerosol particle size distribution was measured via cascade impaction, according to the Comité Européen Normalisé standard, prEN 13544-1, "Respiratory Therapy Equipment: Part 1: Nebulizing Systems and Their Com- ponents." 17 The nebulizer was held upright in a ring stand and connected with a tube (volume $170 \mathrm{~mL}$ ) to an 8-stage cascade impactor (Mark II, Andersen Instruments, Atlanta, Georgia) with size cut-offs of 12.4, 8.0, 6.4, 4.5, 2.9, 1.5, 1.0 , and $0.6 \mu \mathrm{m}$. The vacuum pump was connected to the impactor and run at $15 \mathrm{~L} / \mathrm{min}$, and the flow was periodically monitored with a calibrated flow meter, which minimizes temperature and relative humidity variations. ${ }^{18}$ Thirty seconds after the pump was switched on, the nebulizer compressor was switched on and run until nebulization was complete.

Preliminary experiments indicated that, to prevent sample overload on the impactor stages, the optimal nebulization times were $4 \mathrm{~min}$ and $9 \mathrm{~min}$, respectively, when the drugs were nebulized separately and mixed. The impactor throat and each impactor stage plate were eluted with 0.1-M HCL solution to recover all the drug, and assayed with chromatography. ${ }^{16}$ I analyzed the mass median aerodynamic diameter (MMAD), geometric standard deviation, respirable fraction (percent of aerosol particles smaller than $5 \mu \mathrm{m}$ ), and respirable mass (expressed as a percent of the nominal dose) data with graphics software (KaleidaGraph 4.01, Synergy Software, Reading, Pennsylvania).

\section{Statistical Analysis}

I used 2-way analysis of variance to determinate differences between the nebulizers and between the different formulations. For the different formulations with the same nebulizer, and for the different nebulizers with same formulation, I compared aerosol output, nebulization time, drug output, and aerodynamic characteristics. A $P$ value $<.05$ was considered statistically significant. The analysis was performed with statistics software (Stata 9, StataCorp, College Station, Texas).

\section{Results}

Table 2 shows the aerosol output and nebulization time data. The SideStream and VentStream-Pro aerosol output never significantly differed with the same formulation except for ipratropium when nebulized alone. The aerosol output with the 4 formulations that contained corticosteroids was greater than that of the other two $(P<.001)$. Although always significant, a slightly lower difference was observed between albuterol alone and albuterol mixed with ipratropium and budesonide with VentStream-Pro $(P=.04)$. Only the nebulization time of the different nebulizers for albuterol $(P=.03)$ and ipratropium $(P=.04)$ was statistically different.

Table 3 shows the drug output and residual liquid volume data. By assaying the drug captured on the filters and that remained in the nebulizer reservoir and the circuit after nebulization, I calculated the total drug recovery, 
Table 2. Aerosol Output and Nebulization Time*

\begin{tabular}{|c|c|c|c|c|c|c|}
\hline & Albuterol & Ipratropium & Budesonide & Beclomethasone & $\begin{array}{l}\text { Budesonide }+ \\
\text { Ipratropium }+ \\
\quad \text { Albuterol }\end{array}$ & $\begin{array}{c}\text { Beclomethasone }+ \\
\text { Ipratropium }+ \\
\text { Albuterol }\end{array}$ \\
\hline \multicolumn{7}{|l|}{ Aerosol Output $(\mu \mathrm{g})$} \\
\hline SideStream & $3,426 \pm 38 \dagger$ & $3,183 \pm 43 \dagger+$ & $3,778 \pm 123$ & $3,833 \pm 76$ & $3,704 \pm 30$ & $3,858 \pm 63$ \\
\hline VentStream-Pro & $3,421 \pm 162 \dagger$ & $3,384 \pm 121 \dagger$ & $3,766 \pm 63$ & $3,991 \pm 53$ & $3,651 \pm 79$ & $3,936 \pm 53$ \\
\hline \multicolumn{7}{|c|}{ Nebulization Time (min) } \\
\hline SideStream & $17.9 \pm 0.7 \ddagger$ & $15.9 \pm 0.4 \$$ & $12.4 \pm 0.6$ & $13.2 \pm 0.2$ & $13.7 \pm 0.6$ & $14.1 \pm 0.5$ \\
\hline VentStream-Pro & $11.5 \pm 1.0$ & $12.7 \pm 0.7$ & $13.7 \pm 0.9$ & $13.2 \pm 0.6$ & $12.7 \pm 0.7$ & $16.7 \pm 0.6$ \\
\hline
\end{tabular}

Table 3. Drug Output and Residual Drug After Nebulization*

\begin{tabular}{|c|c|c|c|c|c|c|c|c|c|c|}
\hline & \multicolumn{3}{|c|}{ Albuterol } & \multicolumn{3}{|c|}{ Ipratropium } & \multicolumn{2}{|c|}{ Budesonide } & \multicolumn{2}{|c|}{ Beclomethasone } \\
\hline & $\begin{array}{l}\text { Nebulized } \\
\text { Alone }\end{array}$ & $\begin{array}{c}\text { Nebulized } \\
\text { With } \\
\text { Ipratropium } \\
\text { and } \\
\text { Beclomethasone }\end{array}$ & $\begin{array}{l}\text { Nebulized } \\
\text { With } \\
\text { Ipratropium } \\
\text { and } \\
\text { Budesonide }\end{array}$ & $\begin{array}{l}\text { Nebulized } \\
\text { Alone }\end{array}$ & $\begin{array}{c}\text { Nebulized } \\
\text { With } \\
\text { Albuterol } \\
\text { and } \\
\text { Beclomethasone }\end{array}$ & $\begin{array}{l}\text { Nebulized } \\
\text { With } \\
\text { Albuterol } \\
\text { and } \\
\text { Budesonide }\end{array}$ & $\begin{array}{l}\text { Nebulized } \\
\text { Alone }\end{array}$ & $\begin{array}{l}\text { Nebulized } \\
\text { With } \\
\text { Ipratropium } \\
\text { and } \\
\text { Albuterol }\end{array}$ & $\begin{array}{l}\text { Nebulized } \\
\text { Alone }\end{array}$ & $\begin{array}{l}\text { Nebulized } \\
\text { With } \\
\text { Ipratropium } \\
\text { and } \\
\text { Albuterol }\end{array}$ \\
\hline \multicolumn{11}{|l|}{ Drug Output $(\mu \mathrm{g})$} \\
\hline SideStream & $1,028 \pm 91$ & $634 \pm 74$ & $937 \pm 23 \dagger$ & $580 \pm 33 \dagger$ & $152 \pm 25$ & $251 \pm 68$ & $828 \pm 87 \dagger$ & $192 \pm 28$ & $819 \pm 34 \dagger$ & $298 \pm 28$ \\
\hline VentStream-Pro & $818 \pm 38$ & $498 \pm 51$ & $724 \pm 16$ & $298 \pm 59$ & $131 \pm 17$ & $216 \pm 7$ & $441 \pm 160$ & $177 \pm 6$ & $618 \pm 63$ & $309 \pm 25$ \\
\hline \multicolumn{11}{|l|}{$\begin{array}{r}\text { Drug Output (\% of } \\
\text { nominal dose) }\end{array}$} \\
\hline SideStream & 42 & $25 \ddagger$ & 38 & 52 & $31 \ddagger \S$ & 50 & $37 \ddagger$ & 19 & 46 & 37 \\
\hline VentStream-Pro & 33 & $20 \ddagger$ & 28 & 27 & $26 \S$ & $43 \ddagger$ & 20 & 18 & 34 & 39 \\
\hline \multicolumn{11}{|c|}{$\begin{array}{l}\text { Residual Drug After } \\
\text { Nebulization }(\mu \mathrm{g})\end{array}$} \\
\hline SideStream & $1,060 \pm 46$ & $861 \pm 64$ & $780 \pm 52$ & $421 \pm 57$ & $176 \pm 27$ & $153 \pm 21$ & $1,229 \pm 67$ & $701 \pm 23$ & $1,030 \pm 13$ & $415 \pm 64$ \\
\hline VentStream-Pro & $1,073 \pm 64$ & $815 \pm 33$ & $724 \pm 45$ & $474 \pm 48$ & $163 \pm 23$ & $153 \pm 22$ & $1,320 \pm 47$ & $693 \pm 35$ & $1,080 \pm 16$ & $433 \pm 44$ \\
\hline \multicolumn{11}{|c|}{$\begin{array}{l}\text { * Values are mean } \pm \mathrm{SD} \text {. } \\
\dagger \text { Statistically significant difference for comparison of different nebulizers with the same drug/drug combination. Albuterol alone: } P=.08 \text { Albuterol mixed with ipratropium and beclomethasone: } P= \\
.07 \text { Albuterol mixed with ipratropium and budesonide: } P=.03 \text { Ipratropium alone: } P=.03 \text { Ipratropium mixed with albuterol and beclomethasone: } P=.30 \text {. Ipratropium mixed with albuterol and } \\
\text { budesonide: } P=.44 \text {. Budesonide alone: } P=.048 \text {. Budesonide mixed: } P=.66 \text {. Beclomethasone alone: } P=.03 \text {. Beclomethasone mixed: } P=.65 \text {. } \\
\text { ‡ Statistically significant difference for comparison of one drug nebulized alone versus in combination with other drugs, with the same nebulizer. Albuterol alone versus albuterol mixed with } \\
\text { ipratropium and beclomethasone with SideStream: } P=.04 \text {. Albuterol alone versus albuterol mixed with ipratropium and beclomethasone with VentStream-Pro: } P=.01 \text {. Ipratropium alone versus } \\
\text { ipratropium mixed with albuterol and beclomethasone with SideStream: } P=.003 \text {. Ipratropium alone versus ipratropium mixed with albuterol and budesonide with VentStream-Pro: } P<.001 . \\
\text { Budesonide alone versus budesonide mixed with SideStream: } P<.001 \text {. } \\
\S \text { Statistically significant difference for comparison of different mixtures with the same nebulizer: one bronchodilator versus that bronchodilator mixed with different corticosteroids. Ipratropium with } \\
\text { albuterol and beclomethasone versus ipratropium with albuterol and budesonide for both SideStream and VentStream-Pro: } P<.001 \text {. }\end{array}$} \\
\hline
\end{tabular}

running a mass-balance test throughout the study; the aerosol loss to the environment was in the range of $89 \%<$ total drug recovery $<100 \%$ of total drug in all cases. There was no difference between nebulizers in the amount of drug retained in the reservoir. Drug-mixing had a trend, although not always significant, of reduced drug output with the SideStream, whereas the results with VentStreamPro were more variable.

Table 4 shows the mass median aerodynamic diameter and geometric standard deviation data. Drug-mixing increased MMAD with SideStream, but not with VentStreamPro. Drug-mixing did not significantly change the geometric standard deviation, except for budesonide with
SideStream. However, all the single-drug and mixed-drug nebulizations had heterodisperse aerosols (geometric standard deviation $>1.2 \mu \mathrm{m})$.

Figure 2 shows the respirable-fraction data. The only drug that when nebulized alone, versus in combination with other drugs, modified the respirable fraction was beclomethasone with SideStream $(P=.02)$. The respirable-fraction range was $62-78 \%$ for the bronchodilators and $35-62 \%$ for the corticosteroids. Figure 3 shows the respirable-mass data. Overall, drug-mixing tended to reduce the respirable mass with SideStream, but not always with VentStream-Pro. When nebulized alone, the respirable mass of bronchodilators ranged from $18 \%$ to $40 \%$ of 
Budesonide, Beclomethasone, Albuterol, And Ipratropium Aerosols

Table 4. Mass Median Aerodynamic Diameter and Geometric Standard Deviation*

\begin{tabular}{|c|c|c|c|c|c|c|c|c|c|c|}
\hline & \multicolumn{3}{|c|}{ Albuterol } & \multicolumn{3}{|c|}{ Ipratropium } & \multicolumn{2}{|c|}{ Budesonide } & \multicolumn{2}{|c|}{ Beclomethasone } \\
\hline & $\begin{array}{l}\text { Nebulized } \\
\text { Alone }\end{array}$ & $\begin{array}{c}\text { Nebulized } \\
\text { With } \\
\text { Ipratropium } \\
\text { and } \\
\text { Beclomethasone }\end{array}$ & $\begin{array}{l}\text { Nebulized } \\
\text { With } \\
\text { Ipratropium } \\
\text { and } \\
\text { Budesonide }\end{array}$ & $\begin{array}{l}\text { Nebulized } \\
\text { Alone }\end{array}$ & $\begin{array}{c}\text { Nebulized } \\
\text { With } \\
\text { Ipratropium } \\
\text { and } \\
\text { Beclomethasone }\end{array}$ & $\begin{array}{l}\text { Nebulized } \\
\text { With } \\
\text { Ipratropium } \\
\text { and } \\
\text { Budesonide }\end{array}$ & $\begin{array}{l}\text { Nebulized } \\
\text { Alone }\end{array}$ & $\begin{array}{l}\text { Nebulized } \\
\text { With } \\
\text { Ipratropium } \\
\text { and } \\
\text { Albuterol }\end{array}$ & $\begin{array}{l}\text { Nebulized } \\
\text { Alone }\end{array}$ & $\begin{array}{l}\text { Nebulized } \\
\text { With } \\
\text { Ipratropium } \\
\text { and } \\
\text { Albuterol }\end{array}$ \\
\hline \multicolumn{11}{|l|}{$\operatorname{MMAD}(\mu \mathrm{m})$} \\
\hline SideStream & $2.7 \pm 0.2$ & $3.9 \pm 0.1 \dagger+$ & $3.3 \pm 0.1 \dagger+$ & $2.5 \pm 0.3$ & $3.9 \pm 0.1 \dagger 末$ & $3.0 \pm 0.4$ & $4.2 \pm 0.1$ & $5.0 \pm 0.2 \ddagger$ & $4.8 \pm 0.5$ & $6.2 \pm 0.1 \%$ \\
\hline VentStream-Pro & $3.1 \pm 0.1$ & $3.5 \pm 0.2$ & $2.9 \pm 0.2$ & $3.2 \pm 0.3$ & $3.4 \pm 0.1$ & $2.8 \pm 0.3$ & $4.9 \pm 0.8$ & $4.3 \pm 0.4$ & $5.0 \pm 0.9$ & $5.5 \pm 0.3$ \\
\hline \multicolumn{11}{|l|}{$\operatorname{GSD}(\mu \mathrm{m})$} \\
\hline SideStream & $2.4 \pm 0.1$ & $2.4 \pm 0.1$ & $2.4 \pm 0.0$ & $2.4 \pm 0.1$ & $2.2 \pm 0.1$ & $2.4 \pm 0.1$ & $1.8 \pm 0.1$ & $3.0 \dagger \pm 0.2$ & $1.7 \pm 0.1$ & $1.7 \pm 0.0$ \\
\hline VentStream-Pro & $2.5 \pm 0.1$ & $2.4 \pm 0.0$ & $2.3 \pm 0.1$ & $2.4 \pm 0.2$ & $2.4 \pm 0.2$ & $2.2 \pm 0.1$ & $1.9 \pm 0.1$ & $1.9 \pm 0.0$ & $1.8 \pm 0.0$ & $1.7 \pm 0.0$ \\
\hline
\end{tabular}

$\bar{*}$ Values are mean \pm SD.

$\dagger$ Statistically significant difference for comparison of different nebulizers with the same drug/drug combination. Albuterol alone: $P=.08$. Albuterol mixed with ipratropium and beclomethasone $P=.04$. Albuterol mixed with ipratropium and budesonide: $P=.046$. Ipratropium alone: $P=.059$. Ipratropium mixed with albuterol and beclomethasone: $P=.007$. Ipratropium mixed with albuterol and budesonide: $P=.74$. Budesonide alone: $P=.23$. Budesonide mixed: $P=.054$. Beclomethasone alone: $P=.83$. Beclomethasone mixed: $P=.051$.

¥ Statistically significant difference for comparison of one drug nebulized alone versus in combination with other drugs, with the same nebulizer. Albuterol alone versus albuterol plus beclomethasone via SideStream: $P<.001$. Albuterol alone versus albuterol plus budesonide via SideStream: $P=.03$. Albuterol alone versus albuterol plus beclomethasone via VentStream-Pro: $P=.10$. Albuterol alone versus albuterol plus budesonide via VentStream-Pro: $P=.31$. Ipratropium alone versus ipratropium plus beclomethasone via SideStream: $P<.001$. Ipratropium alone versus ipratropium plus budesonide via SideStream: $P=.29$. Ipratropium alone versus ipratropium plus beclomethasone via VentStream-Pro: $P=.35$. Ipratropium alone versus ipratropium plus budesonide via VentStream: $P=.41$. Budesonide alone versus mixed via SideStream: $P=.002$. Budesonide alone versus mixed via VentStream: $P=.09$. Beclomethasone alone versus mixed via SideStream: $P=.004$. Beclomethasone alone versus mixed via VentStream; $P=.23$.

MMAD = mass median aerodynamic diameter

GSD $=$ geometric standard deviation

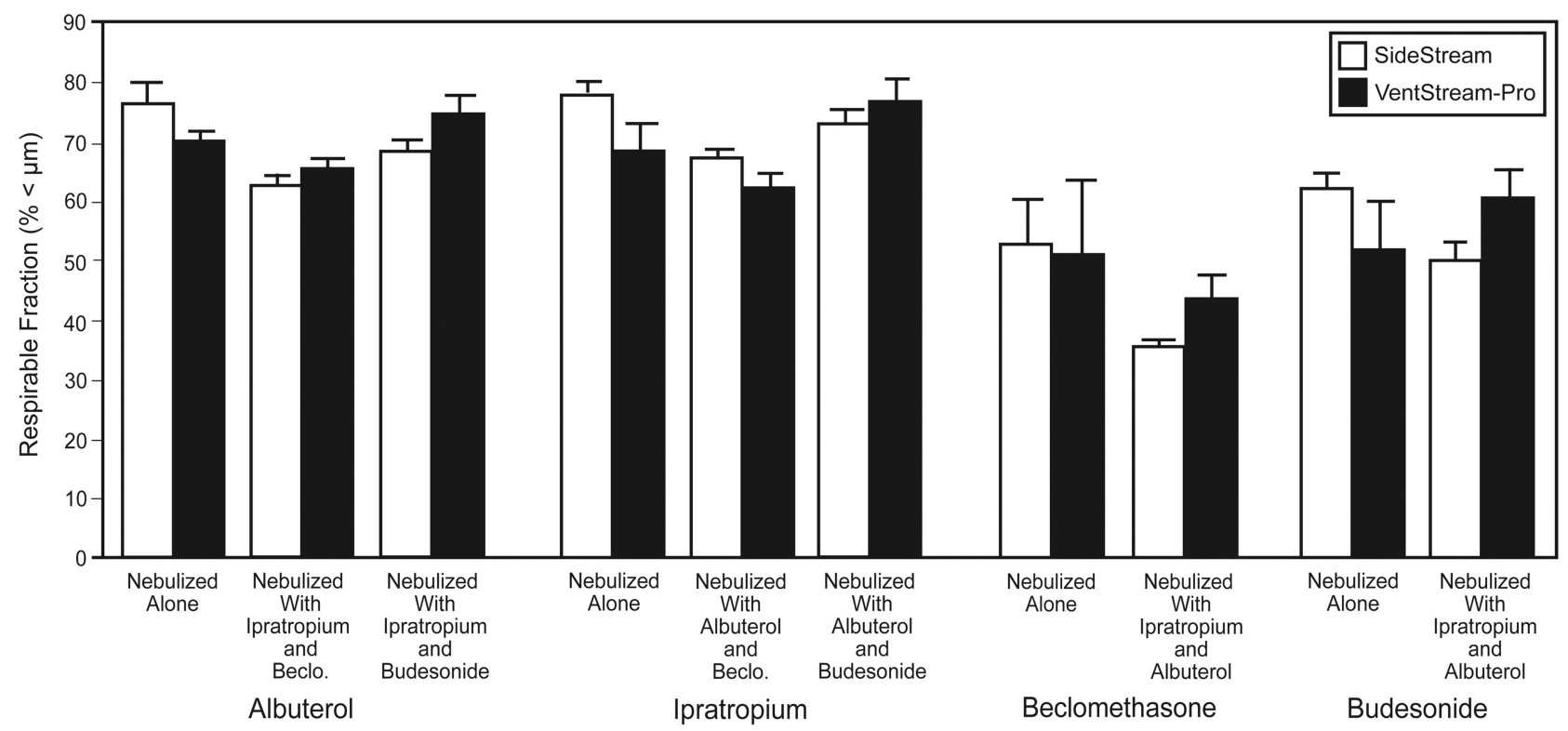

Fig. 2. Respirable fraction expressed as percent of nominal dose. Beclo. = Beclomethasone.

the nominal dose; when mixed, it ranged from $13 \%$ to $37 \%$. When nebulized alone, the respirable mass of corticosteroids ranged from $10 \%$ to $24 \%$ of the nominal dose; when mixed, it ranged from $10 \%$ to $17 \%$.

\section{Discussion}

The primary aim of this study was to evaluate whether mixing of either budesonide or beclomethasone with al- buterol and ipratropium modified the drug output or aerosol particle size distribution. In the past, aerosol output was evaluated only by weighing the nebulizer before and after nebulization. ${ }^{19}$ This method is not accurate in measuring drug output. It was known that the gravimetric measurement, independently of volume fill or concentration of the solvent, overestimates the output of albuterol, compared to the filtering method. ${ }^{20}$ The present results confirm and extend that finding. By gravimetrics I found that the 


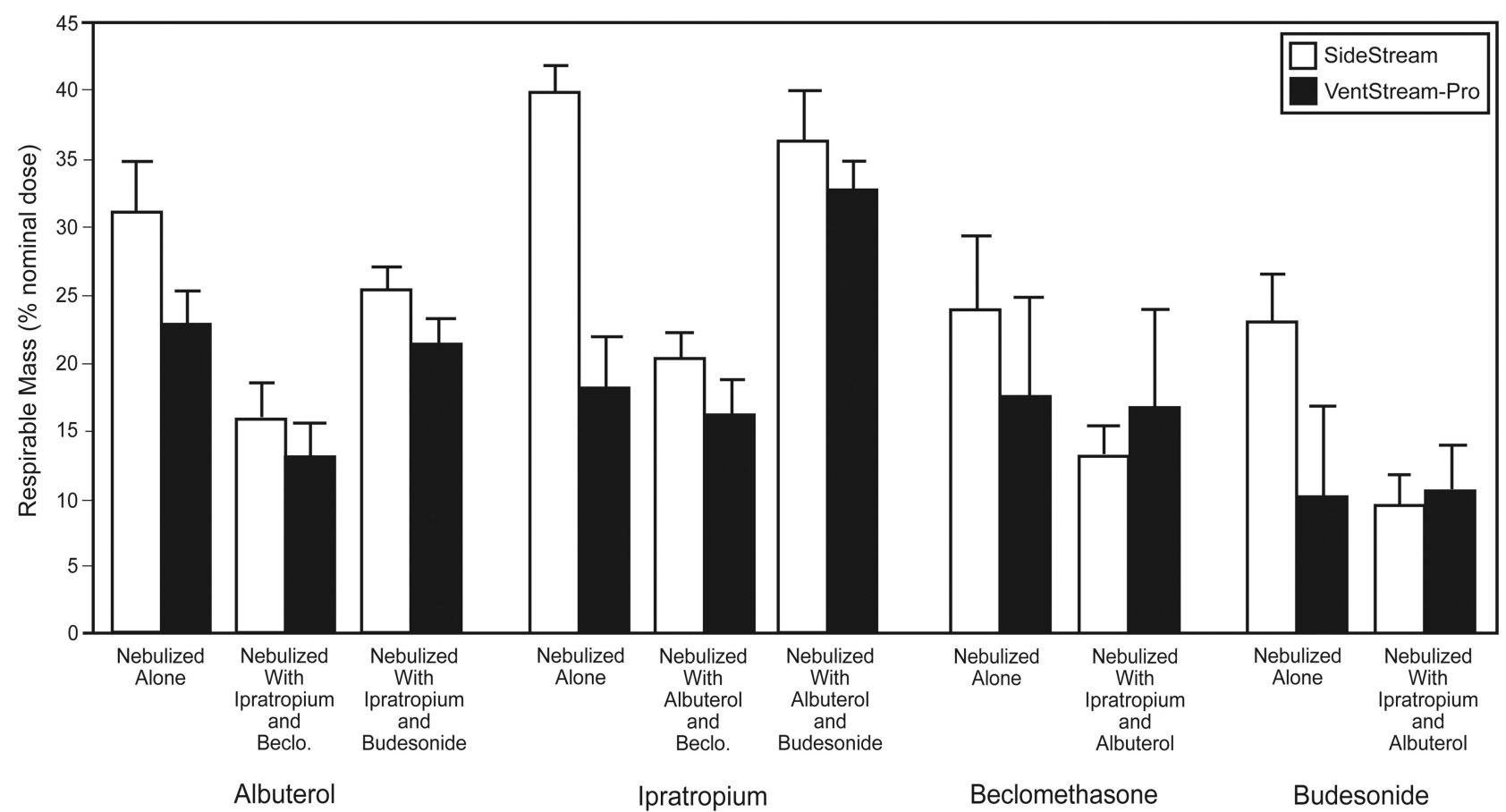

Fig. 3. Respirable mass, expressed as percent of nominal dose. Beclo = beclomethasone.

Comparison of different nebulizers with the same drug/drug combination. $P$ value: Albuterol alone: $P=.24$; albuterol mixed with ipratropium and beclomethasone: $P=.83$; albuterol mixed with ipratropium and budesonide: $P=.68$; ipratropium alone: $P=.02$; ipratropium mixed with albuterol and beclomethasone: $P=.75$; ipratropium mixed with albuterol and budesonide: $P=.85$; budesonide alone: $P=.23$; budesonide mixed: $P=.66$; beclomethasone alone: $P=.77$; beclomethasone mixed: $P=.88$.

Comparison of one drug alone versus in combination with other drugs, with the same nebulizer. $P$ value: Albuterol alone versus mixed with ipratropium and beclomethasone with SideStream: $P=.008$; albuterol alone versus mixed with ipratropium and budesonide with SideStream: $P=.048$; albuterol alone versus mixed with ipratropium and beclomethasone with VentStream-Pro: $P=.047$; albuterol alone versus mixed with ipratropium and budesonide with VentStream-Pro: $P=.054$; ipratropium alone versus mixed with albuterol and beclomethasone with SideStream: $P<.001$; ipratropium alone versus mixed with albuterol and budesonide with SideStream: $P=.47$; ipratropium alone versus mixed with albuterol and beclomethasone with VentStream-Pro: $P=.68$; ipratropium alone versus mixed with albuterol and budesonide with VentStream-Pro: $P=.003$; budesonide alone versus mixed with SideStream: $P=.009$; budesonide alone versus mixed with VentStream-Pro: $P=.73$; beclomethasone alone versus mixed with SideStream: $P=.02$; beclomethasone alone versus mixed with VentStream-Pro: $P=.69$.

formulations containing corticosteroids, both alone and mixed, had a greater aerosol output, but it was only more solvent, not more drug, that was nebulized, as shown by the filtering-method results. So the bronchodilator and the corticosteroid output ranges, respectively, were $20-52 \%$ and $18-46 \%$ of the nominal dose.

I used continuous flow in these experiments, which is a study limitation because constant flow does not mimic the varying flow of the in vivo respiratory cycle. The importance of using a simulated breathing pattern rather than continuous flow in the assessment of nebulizer performances was clearly shown with budesonide, even if that difference was less evident with a breath-enhanced nebulizer such as VentStream-Pro. ${ }^{21}$ Nevertheless, the results for the corticosteroid output were similar to those from the literature using an adult breathing pattern. Nebulizing $2 \mathrm{~mL}$ of budesonide $(0.25 \mathrm{mg} / \mathrm{mL})$ with the Pari ProNeb Turbo/ LC Plus and the PortaNeb/VentStream, Barry and O'Callaghan found drug outputs of $22 \%$ and $10 \%$ of the initial amount, respectively. ${ }^{22}$ With the Pari Inhaler Boy, O'Callaghan $^{23}$ nebulized a lower-concentration brand of beclomethasone than I used in the present study, and found a drug output of about $30 \%$ of the initial charge. With the Pari LC Plus, Vaghi et al ${ }^{24}$ found an output of $27 \%$ of the nominal charge with both beclomethasone and budesonide. More importantly, drug-mixing did not severely compromise drug output, which always remained good.

Drug collection on the inspiratory filter represents all aerosol drug delivered to the patient, not just that deposited in the lungs. Only droplets less than about $5.5 \mu \mathrm{m}$ are generally considered suitable for effective lung delivery. Mixing the drugs tended to increase droplet size, but not always with VentStream-Pro. However, the MMAD of the studied drugs, nebulized alone or mixed, was always acceptable. This finding is in accordance with another recent in vitro study, in which a mixture of beclomethasone and albuterol, nebulized with the BimboNeb and the Nebula nebulizer systems, had mean MMADs of $6.3 \mu \mathrm{m}$ and 
$5.3 \mu \mathrm{m}$, respectively. ${ }^{25}$ Akapo et al, ${ }^{14}$ with the Pari LC Plus (and the Pari ProNeb II Ultra compressor), found that the MMAD of a formoterol-plus-budesonide mixture did not differ from that of single-drug nebulizations. Little other information is available about mixing of corticosteroids with bronchodilators. Berlinski and Waldrep ${ }^{26} \mathrm{ob}-$ served a slightly smaller MMAD with albuterol alone $(2.7 \mu \mathrm{m})$, compared to albuterol plus flunisolide $(3.4 \mu \mathrm{m})$, with the Pari LC Plus. Di Berardino and Scaglione ${ }^{27}$ reported a substantial reduction in respirable fraction when albuterol was mixed with either beclomethasone or flunisolide, but they performed particle size analysis with laser diffraction, which is unsuitable for suspensions such as corticosteroids, because it cannot distinguish between droplets that contain drug and those constituted only of solvent.

The respirable-mass ranges of the bronchodilators and corticosteroids were $13-40 \%$ and $10-24 \%$ of the nominal dose, respectively, so although mixing can modify the respirable mass of the studied drugs, the VentStream-Pro and SideStream, driven by the AirClinic compressor, always provided a good respirable mass. It is noteworthy that mixing beclomethasone or budesonide with the bronchodilators did not substantially reduce the respirable mass, as was previously supposed. ${ }^{27}$ Akapo et al ${ }^{14}$ found that mixing could increase the respirable mass in single-drug nebulization, but that result was possibly due to the different fill volumes used in those experiments. This problem did not occur in the present study, as I always used the same fill volume. However, with regard to the respirable mass, because significant differences between nebulizers have been observed for the corticosteroid and bronchodilator mixtures, I suggest limiting these findings only to the SideStream and VentStream-Pro used with the AirClinic compressor.

Further in vitro studies should assess whether other nebulizers are suitable to nebulize drug mixtures that contain corticosteroids, and the consequences of drug-mixing on $\mathrm{pH}$, osmolality, turbidity, and other physical and chemical properties. More importantly, further study is needed on whether the present study's in vitro findings are clinically relevant. Until clinical studies are available, physicians should be cautious about the prescription of nebulized mixtures.

\section{Conclusions}

The SideStream and VentStream-Pro offer good aerosol performance when nebulizing budesonide or beclomethasone alone, and when mixed with albuterol and ipratropium.

\section{REFERENCES}

1. Dolovich MB. Ahrens RC, Hess DR, Anderson P, Dhand D, Rau JL, et al. Device selection and outcomes of aerosol therapy: evidence- based guidelines: American College of Chest Physicians; American College of Asthma, Allergy, and Immunology. Chest 2005;127(1): 335-371.

2. Barta SK, Crawford A, Roberts CM. Survey of patients' views of domiciliary nebulizer treatment for chronic lung disease. Respir Med 2002;96(6):375-381.

3. Melani AS, Sestini P, Aiolfi S, Barbato N, Canessa P, DeAngelis G, et al; Associazione Italiana Pneumologi Ospedalieri (AIPO) Educational Group. GENebu Project: home nebulizer use and maintenance in Italy. Eur Respir J 2001;18(5):758-763.

4. Marcus P, Oppenheimer EA, Patel PA, Katz LM, Doyle JJ. Use of nebulized inhaled corticosteroids among older adult patients: an assessment of outcome. Ann Allergy Asthma Immunol 2006;96(5): 736-743.

5. Newman SP, Chan HK. In vitro/in vivo comparisons in pulmonary drug delivery. J Aerosol Med Pulm Drug Deliv 2008;21(1):77-84.

6. Nikander K, Turpeinen M, Wollmer P. The conventional ultrasonic nebulizer proved inefficient in nebulizing a suspension. J Aerosol Med 1999;12(2):47-53.

7. Smaldone GC, Cruz-Rivera M, Nikander K. In vitro determination of inhaled mass and particle distribution for budesonide nebulizing suspension. J Aerosol Med 1998;11:113-125.

8. Berg E, Picard RJ. In vitro delivery of budesonide from 30 jet nebulizer/compressor combinations. Respir Care 2009;54(12):16711678.

9. Pujol MS, Menat C, Henon T, Jacquet M, Woronoff Lemsi MC. [Prescriptions of aerosol therapy. A survey of practices at the Besançon University Hospital] Presse Med 2000;29(15):824-828. Article in French.

10. Melani AS, Pirrelli M, Sestini P, DelDonno M, Bonavia M, Canessa $\mathrm{P}$, et al; Associazione Italiana Pneumologi Ospedalieri Educational Group. GENebu Project Equipment and drugs used for home nebulizer therapy in Italy. Monaldi Arch Chest Dis 2002;57(5-6):231236.

11. McKenzie JE, Cruz-Rivera M. Compatibility of budesonide inhalation suspension for four nebulizing solutions. Ann Pharmacother 2004;38(6):967-972.

12. Kamin W, Schwabe A, Krämer I. Physicochemical compatibility of fluticasone-17-propionate nebulizer suspension with ipratropium and albuterol nebulizer solutions. Int J Chron Obstruct Pulmon Dis 2007; 2(4):599-607.

13. Bonasia PJ, McVicar WK, Williams B, Ong S. Chemical and physical compatibility of levoalbuterol inhalation solution concentrate mixed with budesonide, ipratropium bromide, cromolyn sodium, or acetylcysteine sodium. Respir Care 2008;53(12):1716-1722.

14. Akapo S, Gupta J, Martinez E, McCrea C, Ye L, Roach M. Compatibility and aerosol characteristics of formoterol fumarate mixed with other nebulizing solutions. Ann Pharmacother 2008;42(10): 1416-1424.

15. Nicolini G, Cremonesi G, Melani AS. Inhaled corticosteroid therapy with nebulized beclomethasone dipropionate. Pulm Pharmacol Ther 2010;23(3):145-155.

16. Karnes HT, Shiu G, Shah VP. Validation of bioanalytical methods. Pharm Res 1991;8(4):421-426.

17. Comité Européen Normalisé. Respiratory therapy equipment: part 1: nebulizing systems and their components. prEN 13544-1.

18. Dennis JH. Standardization issues: in vitro assessment of nebulizer performance. Respir Care 2002;47(12):1445-1448.

19. Kradjan WA, Lakshminarayan S. Efficiency of air compressor driven nebulisers. Chest 1985;87(4):512-516.

20. Tandon R, McPeck M, Smaldone GC. Measuring nebulizer output. Aerosol production vs. gravimetric analysis Chest 1997;111(5):13611365 . 
21. Barry PW, O'Callaghan C. Drug output from nebulizers is dependent on the method of measurement. Eur Respir J 1998;12(2):463-466.

22. Barry PW, O'Callaghan C. An in vitro analysis of the output of budesonide from different nebulisers. J Allergy Clin Immunol 1999; 104(6):1168-1173.

23. O'Callaghan C. Particle size of beclomethasone dipropionate produced by two nebulisers and two spacer devices. Thorax 1990;45(2): 109-111.

24. Vaghi A, Berg E, Liljedahl S, Svensson JO. In vitro comparison of nebulised budesonide (Pulmicort Respules) and beclomethasone dipropionate (Clenil per aerosol). Pulm Pharmacol Ther 2005;18(2): 151-153.

25. O'Callaghan C, White JA, Jackson JM, Barry PW, Kantar A. Nebulisation of corticosteroids suspensions and solutions with a $\beta_{2}$-agonist. J Pharm Pharmacol 2008;60(5):601-605.

26. Berlinski A, Waldrep JC. Nebulized drug admixtures: effect on aerosol characteristics and albuterol output. J Aerosol Med 2006;19(4): 484-490.

27. Di Berardino L, Scaglione F. Mixing albuterol and corticosteroid is not additive. Allergy 1999;54(9):1012-1013. 